\title{
The Neglected Role of Hematologic Disorders in Pulmonary Embolism
}

\author{
Arnon Nagler \\ Division of Hematology, Sackler Faculty of Medicine, University of Tel Aviv, Israel
}

I read with interest the study of Diana Opincariu et al., published recently in the Journal of Cardiovascular Emergencies (Volume 2 Issue 2), reporting on factors associated with one-year mortality in patients with acute pulmonary embolism (PE). ${ }^{1}$

The authors identified hemodynamic instability, left ventricular hypertrophy, associated pulmonary pathologies or chronic kidney disease as significant predictors of mortality at one year, in patients surviving an acute episode of $\mathrm{PE}$. The article is well written and provides relevant information, studying the most common risk factors in patients with $\mathrm{PE}$, that are encountered in the daily practice in cardiac care units. ${ }^{1}$ Therefore, the conclusions of the study are very valuable for clinical practice. However, after carefully reviewing the study data, I have several comments to make.

The entire study addresses the topic from a narrow clinical perspective, without taking into account the potential risk associated with the presence of coagulation disorders. It has been demonstrated that a significant risk factor for the development of $\mathrm{PE}$ is protein $\mathrm{C}$ or protein $\mathrm{S}$ deficiency. The determination of plasma protein $\mathrm{C}$ and protein $\mathrm{S}$ activity or concentrations could help to identify the presence of congenital thrombophilia, which has been reported in many cases to be associated with a higher risk of embolic events as well as with a worse outcome. ${ }^{2}$ Hyperhomocysteinemia has been also demonstrated to represent a risk factor for recurrent venous thromboembolism, and the presence of these disorders might impact on the survival in patients with PE. ${ }^{3}$ In two studies on a pediatric population with venous thromboembolism who underwent comprehensive thrombophilia screening, protein $\mathrm{S}$ deficiency was identified in $8.2 \%$ and protein $C$ deficiency in $7.4 \%$ of their families, indicating that thrombophilia testing should be performed in all cases with an unknown etiology of PE. 4,5 However, in the study of Opincariu et al., although $25 \%$ from the patient population had no identifiable cause of $\mathrm{PE}$, no thrombophilia testing was performed.

The role of hematologic disorders in the etiology of PE could be related to various factors that are associated with both increased coagulability and hemorrhagic disorders, and the association between pulmonary embolism and thrombotic thrombocytopenic purpura or von Willebrand disease has been described in various publications. ${ }^{6,7}$

Another interesting finding of the study is related to the increased mortality in patients with underlying renal or pulmonary disease. These conditions are usually associated with exacerbated inflammation, and inflammation is often accompanied by a pro-thrombotic state. ${ }^{8}$ As the cause of death is not reported, it would be interesting to find out if the deaths were caused by recurrent episodes of pulmonary embolism caused by thrombotic imbalance resulting from inflammation, rather than being related to the progression of the underlying severe pulmonary or renal disease.

A careful consideration of the thrombophilic status and coagulation imbalance in these patients would be of significant value and should, in my opinion, be included in any future study.

\section{REFERENCES}

1. Opincariu D, Mester A, Ratiu M, et al. Factors Associated with One-Year Mortality in Patients with Acute Pulmonary 
Embolism. Journal of Cardiovascular Emergencies. 2016;2:6370. doi: 10.1515/jce-2016-0010.

2. Liu F, Zhu L, Chen P, Shi Z, Liu S. Two cases of pulmonary thromboembolism associated with protein $\mathrm{C}$ and protein S deficiency and literature review. Zhong Nan Da Xue Xue Bao Yi Xue Ban. 2013;38:971-976. doi: 10.3969/j.issn.16727347.2013.09.018.

3. Reitter-Pfoertner S, Waldhoer T, Mayerhofer $\mathrm{M}$, et al. The influence of thrombophilia on the long-term survival of patients with a history of venous thromboembolism. Thromb Haemost. 2013;109:79-84. doi: 10.1160/TH12-05-0361.

4. Klostermeier UC, Limperger V, Kenet G, et al. Role of protein $\mathrm{S}$ deficiency in children with venous thromboembolism. An observational international cohort study. Thromb Haemost. 2015;113:426-433. doi: 10.1160/TH14-06-0533.
5. Limperger V, Klostermeier UC, Kenet G, et al. Clinical and laboratory characteristics of children with venous thromboembolism and protein C-deficiency: an observational Israeli-German cohort study. Br J Haematol. 2014;167:385393. doi: 10.1111/bjh.13039.

6. Zhu T, Pan K, Wang Y. Successful resuscitation with thrombolysis of pulmonary embolism due to thrombotic thrombocytopenic purpura during cardiac arrest. Am J Emerg Med. 2015;33:132.e3-4. doi: 10.1016/j.ajem.2014.06.025.

7. Berntorp E. Thrombosis in patients with hemorrhagic disorders. Minerva Med. 2013;104:169-173.

8. Riva N, Donadini MP, Ageno W. Epidemiology and pathophysiology of venous thromboembolism: similarities with atherothrombosis and the role of inflammation. Thromb Haemost. 2015;113:1176-1183. doi: 10.1160/TH14-06-0563. 